\title{
BMJ Open Job strain and the incidence of coronary heart diseases: does the association differ among occupational classes? A contribution from a pooled analysis of Northern Italian cohorts
}

\author{
Marco M Ferrario, ${ }^{1,2}$ Giovanni Veronesi, ${ }^{1}$ Lorenza Bertù, ${ }^{1}$ Guido Grassi, ${ }^{3,4}$ \\ Giancarlo Cesana ${ }^{3}$
}

To cite: Ferrario MM, Veronesi G, Bertù L, et al. Job strain and the incidence of coronary heart diseases: does the association differ among occupational classes? A contribution from a pooled analysis of Northern Italian cohorts. BMJ Open 2017;7: e014119. doi:10.1136/ bmjopen-2016-014119

- Prepublication history and additional material is available. To view please visit the journal (http://dx.doi.org/ 10.1136/bmjopen-2016014119).

Received 1 September 2016 Revised 10 October 2016 Accepted 30 November 2016

CrossMark

For numbered affiliations see end of article.

Correspondence to Professor Marco M Ferrario; marco.ferrario@uninsubria.it

\section{ABSTRACT}

Objectives: To assess the association between job strain (JS) and the incidence of coronary heart disease (CHD) in North Italian employed men, adopting a stratified analysis by occupational class (OC).

Methods: The study was conducted on 4103 working men, CHD-free at baseline, enrolled in populationbased and factory-based cohorts. Risk factor measurements and follow-up procedures were carried out adopting the WHO MONICA standardised procedures. OCs were derived from the EriksonGoldthorpe-Portocarero classification. JS categories were defined based on overall sample medians of psychological job demand (PJD) and decision latitude (DL) derived from items of the Job Content Questionnaire, satisfying construct validity criteria. Age-adjusted and risk factors-adjusted CHD HRs were estimated from Cox models, contrasting high-strain (high PJD and low DL) versus non-high-strain categories.

Results: In a median follow-up of 14.6 years, 172 $\mathrm{CHD}$ events occurred, corresponding to a CHD incidence rate of 2.78/1000 person-years. In the overall sample, high-strain compared with non-high-strain workers evidenced a $39 \%$ excess CHD risk, not statistically significant. No association was found among managers and proprietors. Conversely, the HR of high strain versus non-high strain was $1.78(95 \% \mathrm{Cl}$ 1.20 to 2.66) among non-manual and manual workers, with no substantial differences between them. The exclusion of the events occurring in the first 3 years of follow-up did not change the results. Adopting the quadrant-term JS groupings, among manual and nonmanual workers, high-strain and active (high PJD and high $\mathrm{DL}$ ) categories in comparison to the low strain one (low PJD and high DL) showed HRs of 2.92 and 2.47 , respectively.

Conclusions: Our findings support the association of $\mathrm{JS}$ and $\mathrm{CHD}$ incidence among manual and non-manual workers. The non-high strain may not be the best reference category, when assessing the contribution of JS in determining CHD incidence.

\section{Strengths and limitations of this study}

- A recently published meta-analysis and subsequent papers have drastically reduced the role of job strain (JS), measured by the Job Content Questionnaire (JCQ), as a primary risk factor for coronary heart disease (CHD), but some methodological shortcomings have been highlighted.

- In our pooled analysis with population-based and factory-based cohorts and a wide range of job titles, we assessed the association between JS and CHD adopting some methodological refinements: we selected relevant JCQ items which showed satisfactory construct validity, and we performed a stratified analysis by occupational classes, motivated by the knowledge that stressors in salaried workers and other professional categories may have different contents.

- We explored the association using as the reference category low JS, instead that the wider non-high JS category, which nullifies the separate effects of control and demands at work, focusing merely on the joint effect.

- Our findings showed that the CHD risks were higher among high JS manual and non-manual workers only, suggesting that JCQ better grasps JS in low-wage working categories; and the CHD risk increased substantially in high JS when compared with low-strain only.

- The study did not include women due to the low incidence rate, and the small sample size anyhow deserves replications in different contexts to enhance confidence in results.

Organisational stressors at the work place and sedentary activities are the two most common work-related cardiovascular disease (CVD) risk factors in postindustrialised societies. $^{1}$ The job demand-control model, ${ }^{2}$ developed by Karasek in the late 1970s is a widely used questionnaire to assess perceived 
work stress conditions. It is based on two major constructs: psychological job demand (PJD) and decision latitude (DL), defining high-strain, active, passive and low-strain categories.

Belkic et $a \hat{l}$ reviewing 17 prospective cohort, 9 casecontrol and 8 cross-sectional studies, concluded in favour of a positive association between job strain (JS) and CVD in men. Kivimaki et $a t^{4}$ in a meta-analysis of cohort studies estimated an overall age-adjusted $43 \%$ excess risk for high JS, assessed with the demandcontrol model. This report combined HRs published by studies using different end points, some reporting combining estimates for men and women, and some adopting the approximate job title-imputed method to estimate exposures. This paper reported higher relative risks for the effort-reward imbalance model ${ }^{5}$ and injustice at work too. A recent paper, based on a collaborative pooled analysis including mainly unpublished (10 out of 13) and published cohort studies, found an overall gender-adjusted and age-adjusted HR for high versus non-high JS of 1.23 (95\% CI 1.10 to 1.37). The non-high JS reference group combines active, passive and low-strain original categories. Based on this low excess risk and an arguable estimate of the high JS prevalence, the authors calculated a small population-attributable risk of 3-4\%. ${ }^{6}$

This publication stimulated an intense debate in the scientific community, ${ }^{7-13}$ and many scientists argued that some shortcomings had contributed to bias the results to the null association. Among them, it is noteworthy to mention the low participation rates and the predominance of white collars in comparison to blue collars. Both these selection biases may have produced a reduced recruitment of more stressed workers, which is a frequently reported problem in these studies. Another potential bias may be due to the misclassification of exposure as JS may change overtime, due to the predominance of different stressors in the work organisations in different time periods. A recent letter ${ }^{14}$ highlighted some methodological and conceptual limitations related to the evaluation of JS. Some of them are arguable and some can only be addressed in future studies, as available data from most recent studies in psychosocial CHD epidemiology were not designed and did not collect the required information. ${ }^{14}$

The aim of the present paper is to assess the association between JS and the incidence of CHD in pooled analysis of population-based and factory-based North Italian cohorts of employed men, in particular focusing on a stratified analysis based on occupational classes. In a previous paper, ${ }^{15}$ we found that JS contributes to explain the excess CHD risk in manual compared with non-manual workers, but not the one observed in managers and self-employers. This finding may imply that the JCQ model better describes strain conditions among salaried manual and non-manual workers only. We reported HRs for the entire follow-up period and after exclusion of the events occurred in the first 3 years, to investigate reverse causation.
METHODS

\section{Study cohorts}

As a part of the WHO-MONICA Project, three surveys of the Brianza population (located North of Milan) took place over a 10-year period (1986-1987, 1989-1990 and 1993-1994) to estimate coronary risk factor changes over time. ${ }^{15}$ In each survey a 10-year age-stratified and gender-stratified random sample was drawn from municipality roles from 25 to 64 years old residents in five arearepresentative towns. The participation rates were $70.1 \%, 67.2 \%$ and $70.8 \%$ respectively. The PAMELA (Pressioni Arteriose Monitorate E Loro Associazioni) study was another population survey, conducted in $1991-1992,{ }^{16}$ with the sampling procedure applied to the 25-74 years old residents of the city of Monza, the largest town in Brianza. The participation rate was $66.9 \%$ among people up to 65 years of age. The overall sample size of individuals who were free of CHD and employed at the time of recruitment was 2350 men and 1334 women.

The SEMM (Surveillance of Employees of the Municipality of Milan) study recruited employees of six departments of the Milan Municipality, screened for CVD risk factors between May 1991 and March 1996. The cohort contributed to the JACE Study. ${ }^{17}$ The participation rates were $75.3 \%$ for men and $76.2 \%$ for women, respectively; and the overall sample size of the SEMM cohort, free of CHD at baseline, was of 2569 men and 5254 women. Women were not included in the analysis due to low number of CHD events (46 events in all the cohorts). The study approvals were obtained from the Ethical Committee of the University Hospital of Monza.

\section{Occupational classes}

As reported in a previous paper, ${ }^{15}$ we derived Erikson-Goldthorpe-Portocarero (EGP) classes. To achieve sufficient statistical power, EGP classes were aggregated in three occupational classes, as follows: professionals, administrators, managers, proprietors and self-employers (EGP classes I, II and IV, called here briefly managers and proprietors), non-manual (EGP classes III and V) and manual (skilled and unskilled, EGP classes VI and VII) workers.

\section{JS scales and scores}

The Job Content Questionnaire (JCQ) was administered to all employed workers, using two different versions sharing the same core items. In the MONICA Brianza and PAMELA studies as well as for employees of the two first recruited departments of the SEMM study, the short MONICA-MOPSY version ${ }^{18}$ was used. The extended version of JCQ was instead adopted for the remaining four SEMM departments, when the study was included into the JACE Project. ${ }^{16}$ In the online supplementary table S1 the original items for demand and control are reported for both questionnaires. The common items assessing PJD and DL, each on a four-point scale ranging from completely agree to completely disagree, 
were used. A comparability analysis ${ }^{19} 20$ showed that equivalent PJD and DL scores and subscores can be calculated from both questionnaires.

We derived the conventional four JCQ categories based on the quadrant approach, with high strain defined as PJD values higher than the overall sample median and DL values lower than or equal to the median. The remaining three JS categories, that is, active, passive and low strain were also defined according to the standard criteria. ${ }^{2}$ These three last strain categories were collapsed in a unique category, called non-high JS, to allow direct comparisons with the results reported by the recent pooled-cohort meta-analysis. ${ }^{6}$

\section{Measurements of other risk factors at baseline}

In MONICA surveys, cardiovascular risk factors were collected at baseline strictly adhering to the standardised procedures and quality standards of the WHO-MONICA Project (http://www.ktl.fi/publications/monica/manual/ index.htm). In the PAMELA and in the SEMM studies, risk factors were measured based on MONICA-like procedures. In brief, blood pressure was measured on sitting participants at rest for at least $10 \mathrm{~min}$, using a standard mercury sphygmomanometer equipped with larger cuff bladders if needed. The study variable for systolic blood pressure is the average of two measurements taken $5 \mathrm{~min}$ apart. Venous blood specimens were taken from the antecubital vein in fasting participants (12 hours or more). Serum total cholesterol and high-density lipoprotein (HDL) cholesterol were measured by an enzymatic method. Blood glucose was determined on the same samples by an enzymatic method.

From standardised interview information on cigarette smoking habits was available and dichotomised as current versus past smokers/never-smokers in this analysis. Diabetes mellitus was defined using self-reported diagnoses and information on insulin and oral hypoglycaemic treatments or based on a fasting blood glucose exceeding $126 \mathrm{mg} /$ dL. Self-reported information on hospitalisation for myocardial infarction, unstable angina pectoris and coronary revascularisation was used to define a positive history of coronary event at baseline. Items on educational attainment were part of the standardised questionnaire, and it was dichotomised as 'low' (less than high school) and 'high' (high school or more).

\section{Study end points and follow-up procedures}

All participants were followed from the baseline examination until first cardiovascular event, emigration, death, 80th birthday or 31 December 2008, whichever came first, based on locally adapted procedures, developed within the MORGAM Project (http://www.thl.fi/ publications/morgam/manual/followup/fumethod.htm). Vital status was actively investigated for all participants, including those who moved to different towns in Italy, and death certificates were obtained from local health districts. Suspected fatal events were identified on the basis of selected underlying causes of death, International Classification of Diseases (ICD)-9 codes 410-414. Suspected non-fatal events were identified based on ICD-9 hospital discharge codes: 410-411 for acute coronary events, and 36.0-9 for coronary revascularisation. Acute events were further investigated and adjudicated according to the MONICA diagnostic criteria. The study end point is the occurrence of a first major acute coronary event (myocardial infarction, acute coronary syndrome), fatal or non-fatal, or coronary revascularisation. The follow-up was completed for $98.9 \%$ of them, with no differences across cohorts and occupational classes.

\section{Statistical analysis}

Of the 4827 male workers in the age range 25-64 years, we excluded 724 participants with missing values of JCQ items or CHD risk factors, and hence the final sample size was 4103. We calculated the age-adjusted mean (prevalence) of major CHD risk factors by occupational class and strain categories from generalised linear models, and tested differences among groups using Wald $\chi^{2}$ tests.

Factor analysis with varimax rotation and Cronbach's $\alpha$ coefficients were used to assess the construct validity and internal consistency of JCQ items, respectively. These analyses were carried out on the population-based cohorts, characterised by wide job title variability.

Cox proportional hazards model with lifespan (attained age) on the time scale was adopted to study the associations between the risk of CHD event and JS, dichotomised for most analyses in high strain versus non-high strain (reference category comprising passive, active and low strain), adjusting for major risk factors and a dummy variable to indicate the study type (population-based vs factory-based). Stratified analyses were carried out adding a JS $\times$ occupational class interaction term in the models; the $\mathrm{p}$ value for the interaction term represented the formal test for the hypothesis of no change in the association between JS and CHD in different occupational classes (Wald $\chi^{2}$ test). We also performed a separate analysis, using the four JCQ categories (with low strain as reference group). The analyses were performed using the Statistical Analysis System (V.9.4, SAS Institute, Cary, North Carolina, USA). The figure was drawn using the $\mathrm{R}$ software (R Foundation for Statistical Computing, Wien, Austria. http://www.R-project.org/).

\section{RESULTS}

In a median follow-up time of 14.6 years (IQR 13.217.6 years), 172 incident major coronary events occurred in our study sample, corresponding to a cumulative incidence rate of 2.78/1000 person-years. Age-adjusted rates among managers and proprietors and non-manual and manual workers were 3.1 (95\% CI 2.32 to 4.14 ) and 1.97 (1.60 to 2.41), respectively. The exclusion of individuals with missing data did not alter the excess risk in 
managers and proprietors with respect to the nonmanual and manual workers (see online supplementary table S5).

As shown in online supplementary table S2, the results of the factor analysis carried out on the populationsbased MONICA-PAMELA samples, evidenced a satisfactory construct validity of JCQ items, with the notable exception of one item of skill discretion (SD), 'do not repeat things over and over', and two items of PJD, 'work very fast' and 'work very hard'. Since these items did not contribute to the definition of the expected constructs, they were excluded and the scores calculated with the residual available items. Cronbach's $\alpha$ coefficients were 0.70 and 0.75 for DL and 0.53 and 0.58 for PJD among managers and proprietors and non-manual and manual workers, respectively.

Table 1 shows the distributions of main sociodemographic variables, JS categories and cardiovascular risk factors in the entire sample and in the two OCs. Non-manual and manual workers were younger and less educated than managers and proprietors. In the entire sample, $26 \%$ were classified at high strain, as expected due to the quadrant-term approach based on medians and the orthogonality between the constructs (Pearson correlation coefficient between PJD and DL was -0.09). The highest prevalence of high strain was found among non-manual and manual workers, while active and lowstrain categories were prevalent among managers and proprietors. Managers and proprietors showed higher age-adjusted mean values of total cholesterol, but were less likely to smoke than non-manual and manual workers (all $\mathrm{p}<0.05)$. Conversely, the EGP-aggregated occupational class did not differ for mean systolic blood pressure and HDL cholesterol, nor for prevalence of diabetes (all $\mathrm{p}>0.2$ ). As shown in online supplementary table S3, none of the considered risk factors showed statistically significant differences between the four JCQ categories.

Table 2 shows the results of the analysis assessing the association between JS and CHD incidence, for the entire sample and by occupational classes. In the entire sample, high-strain participants evidenced an overall higher HR of 1.39 (95\% CI 0.99 to 1.97) in comparison with non-high strain, which was confirmed even after the exclusion of the first 3 years of follow-up ( $\mathrm{HR}=1.39$, 0.96 to 2.03). No increased hazard of events for high versus non-high strain was found among managers and proprietors, with HRs ranging from 0.71 to 0.61 , both not statistically significant. Conversely, the HR for high versus non-high JS was 1.78 (1.20 to 2.66) among nonmanual and manual workers, which again did not substantially change when events in the first 3 years were excluded (HR=1.80; 1.17 to 2.76 ). The JS $\times$ occupational class interaction term was statistically significant $(p=0.04)$, suggesting the presence of heterogeneity by occupational class in the association between JS and CHD. Finally, these findings were confirmed when population-based and factory-based cohorts were analysed separately (see online supplementary table S4). When manual and non-manual workers were analysed separately, as table 3 shows, the HRs for the high-strain versus non-high-strain workers were 1.94 (95\% CI 1.13

Table 1 Distribution of sociodemographic characteristics and age-adjusted mean and prevalence of major CVD risk factors at baseline, in the entire sample and by aggregated Erikson-Goldthorpe-Portocarero occupational classes

\begin{tabular}{|c|c|c|c|c|}
\hline & \multirow[b]{2}{*}{ Entire sample } & \multicolumn{2}{|c|}{ Occupational class } & \multirow[b]{2}{*}{ p Value } \\
\hline & & $\begin{array}{l}\text { Managers and } \\
\text { proprietors }\end{array}$ & $\begin{array}{l}\text { Non-manual and } \\
\text { manual workers }\end{array}$ & \\
\hline Subjects CHD-free at baseline, $n$ & 4103 & 819 & 3284 & - \\
\hline Age, years & $40.9(9.3)$ & $44.0(10.3)$ & $40.1(8.8)$ & $<0.0001^{*}$ \\
\hline High school diploma or higher (\%) & 39.4 & 45.8 & 37.8 & $<0.0001 \dagger$ \\
\hline High Job Strain (\%) & 26.0 & 12.9 & 29.2 & $<0.0001 \dagger$ \\
\hline Active (\%) & 14.8 & 23.6 & 12.6 & \\
\hline Passive (\%) & 35.6 & 24.2 & 38.5 & \\
\hline Low job strain (\%) & 23.7 & 39.3 & 19.8 & \\
\hline Systolic blood pressure, $\mathrm{mm} \mathrm{Hg}$ & $127.2(16.2)$ & 126.7 & 127.5 & $0.22 \ddagger$ \\
\hline Total cholesterol, mg/dL & 211.4 (41.3) & 215.5 & 210.7 & $0.002 \ddagger$ \\
\hline HDL cholesterol, mg/dL & $49.5(12.9)$ & 49.4 & 49.6 & $0.79 \ddagger$ \\
\hline Current cigarette smokers (\%) & 39.2 & 35.8 & 40.0 & $0.03 \ddagger$ \\
\hline Diabetes mellitus (\%) & 2.6 & 2.8 & 2.3 & $0.3 \ddagger$ \\
\hline Median follow-up, years & 14.6 & 17.2 & 14.0 & - \\
\hline CHD first fatal or non-fatal events, $n$ & 172 & 64 & 108 & - \\
\hline \multicolumn{5}{|c|}{$\begin{array}{l}\text { Men were } 25-64 \text { years old and employed at time of recruitment. } \\
\text { Unless, otherwise indicated, the numbers reported in the table are means and SDs. } \\
{ }^{*} \text { ANOVA F-test. } \\
+\chi^{2} \text { Test. } \\
+ \text { Wald } \chi^{2} \text { test (2df) from generalised linear model adjusted for age. Mean and prevalence of risk factors estimated at the sample age mean of } \\
41 \text { years. } \\
\text { ANOVA, analysis of variance; CHD, coronary heart disease: HDL, high-density lipoprotein. }\end{array}$} \\
\hline
\end{tabular}


Table 2 Multivariate-adjusted HRs and 95\% Cls of first CHD event, for HS versus no HS, as reference category

\section{Entire sample}

\begin{tabular}{|c|c|c|c|c|c|c|c|c|c|c|c|c|c|}
\hline & \multicolumn{4}{|c|}{ Entire sample } & \multicolumn{9}{|c|}{ Occupational class } \\
\hline & \multirow[b]{2}{*}{$\mathbf{N}$} & \multirow[b]{2}{*}{ \#CHD } & \multirow[b]{2}{*}{ HR } & \multirow[b]{2}{*}{$95 \% \mathrm{Cl}$} & \multicolumn{4}{|c|}{ Managers and proprietors } & \multicolumn{4}{|c|}{$\begin{array}{l}\text { Manual and non-manual } \\
\text { workers }\end{array}$} & \multirow[b]{2}{*}{ p Value* } \\
\hline & & & & & $\mathbf{N}$ & \#CHD & HR & $95 \% \mathrm{Cl}$ & $\mathbf{N}$ & \#CHD & HR & $95 \% \mathrm{Cl}$ & \\
\hline \multicolumn{14}{|c|}{ Job strain categories } \\
\hline \multicolumn{14}{|c|}{ All events in the entire follow-up period included } \\
\hline No HS & 3038 & 126 & REF & & 713 & 57 & REF & & 2325 & 69 & REF & & \multirow[t]{2}{*}{0.04} \\
\hline HS & 1065 & 46 & 1.39 & 0.99 to 1.97 & 106 & 7 & 0.71 & 0.32 to 1.56 & 959 & 39 & 1.78 & 1.20 to 2.66 & \\
\hline \multicolumn{14}{|c|}{ Events occurred after the first 3 years of follow-up } \\
\hline No HS & 3002 & 108 & REF & & 697 & 47 & REF & & 2305 & 61 & REF & & \multirow[t]{2}{*}{0.04} \\
\hline HS & 1049 & 39 & 1.39 & 0.96 to 2.03 & 102 & 5 & 0.61 & 0.24 to 1.55 & 947 & 34 & 1.80 & 1.17 to 2.76 & \\
\hline \multicolumn{14}{|c|}{$\begin{array}{l}\text { MONICA Brianza, PAMELA and SEMM cohorts. Men were } 25-64 \text { years old and employed at time of recruitment. } \\
\text { HRs estimated from Cox regression models with age as the time scale, adjusted for study type (population-based vs factory-based), systolic } \\
\text { blood pressure, total cholesterol, HDL cholesterol, diabetes and current smokers. Job strain categories are based on items of Psychological } \\
\text { Job Demand and Decision Latitude. } \\
\text { "p Value for interaction test between occupational class and high-strain (1 df Wald } \chi^{2} \text { test). } \\
\text { CHD, coronary heart disease; HDL, high-density lipoprotein; HS, high job strain; no HS, non-high job strain; PAMELA, Pressioni Arteriose } \\
\text { Monitorate E Loro Associazioni; SEMM, Surveillance of Employees of the Municipality of Milan. }\end{array}$} \\
\hline
\end{tabular}

Table 3 Multivariate-adjusted HRs and 95\% Cls of first CHD event, for HS versus no HS (reference category), among non-manual and manual workers only

\begin{tabular}{|c|c|c|c|c|c|c|c|c|c|}
\hline & \multicolumn{4}{|c|}{ Non-manual workers } & \multicolumn{4}{|c|}{ Manual workers } & \multirow[b]{2}{*}{ p Value* } \\
\hline & $\overline{\mathbf{N}}$ & \#CHD & HR & $95 \% \mathrm{Cl}$ & $\mathbf{N}$ & \#CHD & HR & $95 \% \mathrm{Cl}$ & \\
\hline \multicolumn{10}{|c|}{ Job strain categories } \\
\hline \multicolumn{10}{|c|}{ All events in the entire follow-up period } \\
\hline No HS & 1067 & 32 & REF & & 1258 & 37 & REF & & \multirow{2}{*}{0.7} \\
\hline HS & 399 & 17 & 1.70 & 0.94 to 3.08 & 560 & 22 & 1.94 & 1.13 to 3.32 & \\
\hline \multicolumn{10}{|c|}{ Events occurred after the first 3 years of follow-up } \\
\hline No HS & 1058 & 27 & REF & & 1247 & 34 & REF & & \multirow{2}{*}{0.7} \\
\hline HS & 394 & 14 & 1.68 & 0.88 to 3.23 & 553 & 20 & 1.95 & 1.11 to 3.43 & \\
\hline
\end{tabular}

MONICA Brianza, PAMELA and SEMM cohorts. Men were 25-64 years old and employed at time of recruitment.

HRs estimated from Cox regression models with age as the time scale, adjusted for study type (population-based vs factory-based), systolic blood pressure, total cholesterol, HDL cholesterol, diabetes and current smokers. Job strain categories are based on items of Psychological Job Demand and Decision Latitude.

${ }^{*} p$ Value for interaction test between occupational class and high strain ( $1 \mathrm{df}$ Wald $\chi^{2}$ test).

CHD, coronary heart disease; HDL, high-density lipoprotein; HS, high job strain; no HS, non-high job strain; PAMELA, Pressioni Arteriose Monitorate E Loro Associazioni; SEMM, Surveillance of Employees of the Municipality of Milan.

to 3.32 ) and 1.70 (95\% CI 0.94 to 3.08) for manual and non-manual workers, respectively. There was no evidence of occupation $\times \mathrm{JS}$ interaction $(\mathrm{p}=0.7)$. To maximise the available number of events, this analysis was carried out including the entire follow-up period, but nevertheless, wide CIs acknowledge the poor statistical power.

Table 4 shows the results of the association analysis between JS and CHD when the four JCQ quadrant-term categories are kept separated, including all events that occurred in the entire follow-up period, to maximise the available statistical power. Compared with the low-strain group, the high strain non-manual and manual workers evidenced HR of 2.92 (95\% CI 1.54 to 5.51), higher than when using the non-high-strain group as the reference category. In addition, a risk excess was also found for active workers $(2.47 ; 1.17$ to 5.23$)$, indicating that the demand dimension of JCQ in these workers is playing a major role in increasing the CHD risks. As shown in figure 1, the survival curve of low strain in comparison with all the other JS categories diverged already in the first years of follow-up, and persisted later on (panel A). This observation is in support of the detected small effect of reverse causation assessed with the exclusion of the events that occurred during the first 3 years of follow-up. Moreover, the increase in cumulative risk over attained age (figure 1, panel B) indicates that high strain men at the age of 50 years have the same cumulative risk of low strain men a decade older (figure 1, panel B).

\section{DISCUSSION}

In summary, in the investigated North Italian employed male pooled cohort we found a small increase in risk of CHD events in high JS when compared with non-high JS workers of $39 \%$, not statistically significant. This estimate replicates the findings of recent meta-analyses, extending their results to a Southern European country with 


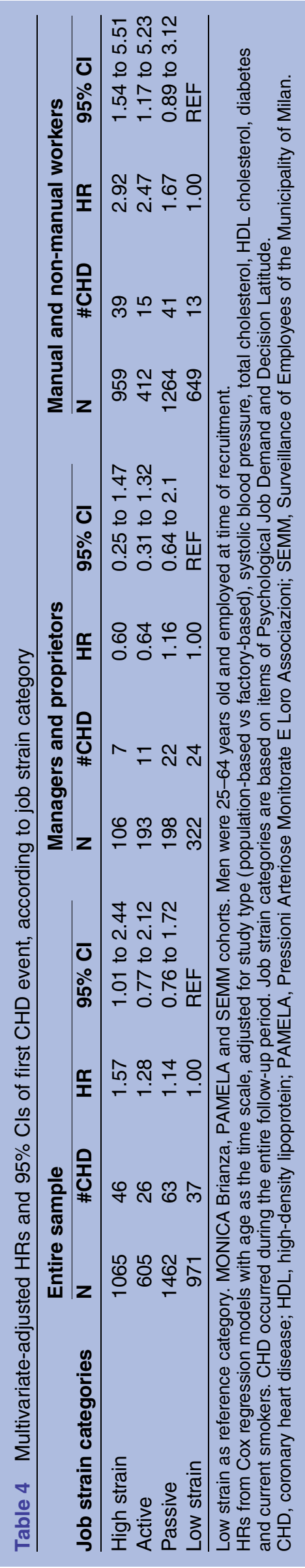

low CHD incidence rates. ${ }^{6}{ }^{11}$ The novelty of our paper relates to results of the stratified analysis, which showed an excess risk of $78 \% \quad(\mathrm{HR}=1.78 ; 95 \%$ CI 1.20 to 2.66) among high-strain non-manual and manual workers. In this occupational class, when the four JCQ categories were separately analysed, the relative risk of CHD events of high-strain versus low-strain participants increased to 2.92 (95\% CI 1.54 to 5.51). It is noteworthy mentioning that the HR for active versus low-strain workers was also elevated ( $\mathrm{HR}=2.47 ; 1.17$ to 5.23$)$, indicating that the association can be biased towards the null hypothesis when active, low-strain and passive men are grouped in a unique non-high-strain class.

The use of JCQ constructs based on the results of factor validity assessment has evidenced satisfactory internal consistency and reliability of the scores. The SD item 'do not repeat things over and over' may have different meanings in a variety of job profiles, working environments and countries; and it may not always connote monotony. ${ }^{21}$ Two items of demand 'work very fast' and 'work very hard' assume minor importance in postindustrial work forces, while items describing pressure for having the work done or conflicting demands are stressors that still continue to characterise present day working conditions, as also reported by other authors. $^{22}$ This observation requires further investigations, as it points to the conclusion that the established JCQ may be well suited to grasp the working conditions of salaried workers, in the low levels of organisation only. The stressful aspects of job characteristics among people ranking at the higher level of organisations are probably related to prolonged working hours and excessive competitiveness, which are not adequately investigated by the actual formulation of the JCQ. ${ }^{23}$

We did not find relevant differences in the distribution of traditional cardiovascular risk factors, including systolic blood pressure, cholesterol as well as the prevalence of diabetes and cigarette smoking, among JCQ categories. In the population-based sample we did find differences among JS categories in the 24-hour systolic blood pressure means, but not when using clinical blood pressure measurements in the same age range. ${ }^{24}$ This observation is in line with previous findings supporting the major importance of a direct, rather than an indirect, effect of JS on the cardiovascular system. ${ }^{21}$ This direct effect is assumed to be attributable to the effect on psychobiological processes, as documented by studies which have found a reduced heart rate variability ${ }^{25}$ and alterations of the hormonal or immune systems. ${ }^{26}$

Among the strengths of the present study are the long follow-up period, the standardisation of the methods to collect risk factors at baseline and to validate events, as they have been carried out adhering to the procedures of the MONICA and MORGAM studies. Among the limitations, we acknowledge that our findings are on men only. We did not include women, due to the low number of events, which did not allow us to further stratify the analyses by occupational classes. We did not explore a 
A

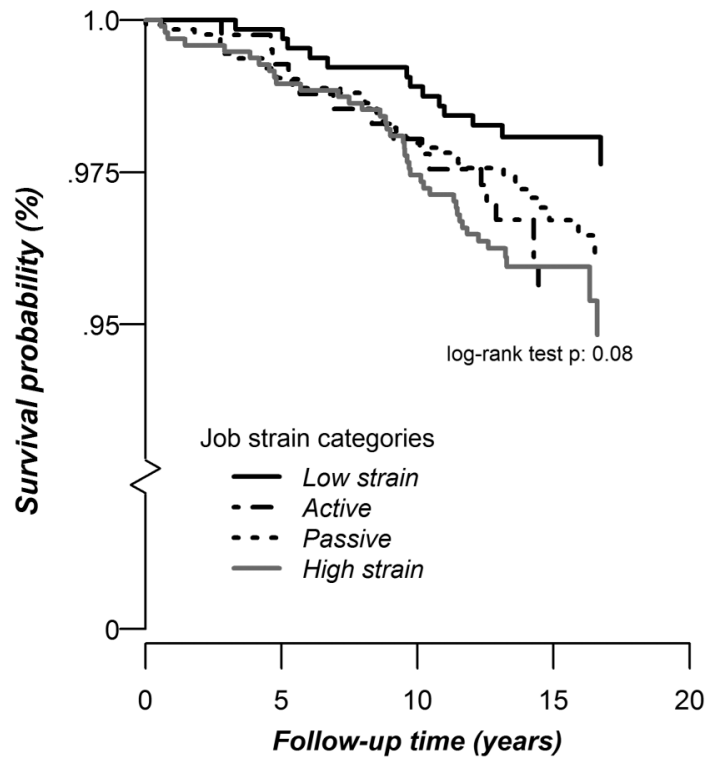

Cumulative risk of CHD by attained age

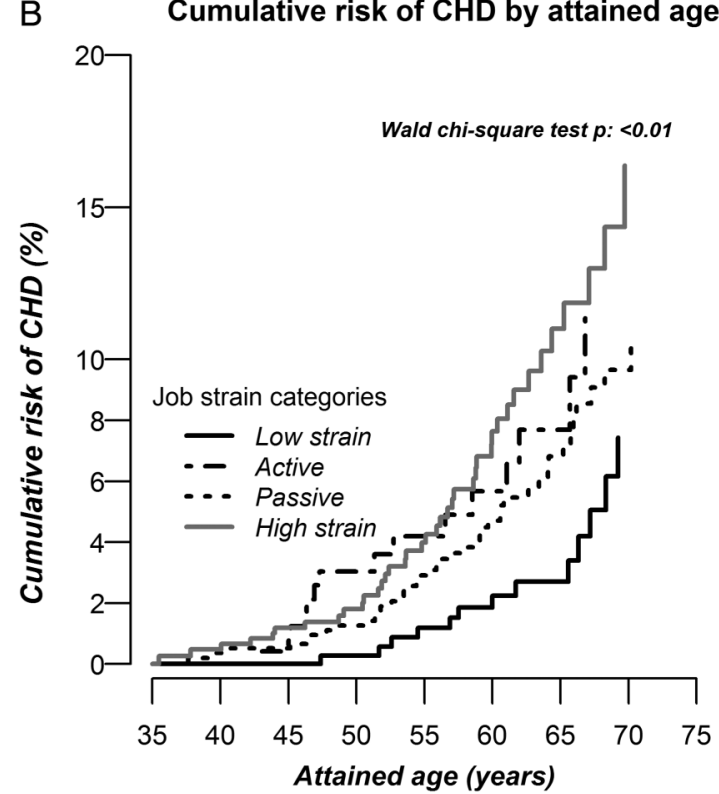

Figure 1 Survival curves (panel A, left) and cumulative risk of coronary heart disease by attained age (panel B, right) in the four JCQ quadrant-term categories, among the occupational class of non-manual and manual workers. Men were 25-64 years old and employed at time of recruitment. JCQ, Job Content Questionnaire; CHD, coronary heart disease.

dose-response relationship, but our findings support the major role of PJD in determining the increased CHD risk, as both high-strain and active workers showed the higher risks when compared with low-strain participants. We also did not explore the interaction effects with other work-related risk factors like social support and physical inactivity, as well as with behavioural risk factors. ${ }^{27}{ }^{28}$ As we do have these baseline data for some of the cohorts, we will investigate these interactions in future reports, hoping to contribute to the current interest of the scientific community on these topics. ${ }^{29-33}$ Finally, we did not collect data at baseline on other complementary theoretical models of stressful work, in particular the effort-reward imbalance model, which has shown remarkable associations with CVD and CHD outcomes. $^{45}$

In conclusion, our findings support the association between JS and CHD incidence in manual and nonmanual workers, not among managers and proprietors. This can be attributable to the better chances of the present formulation of the JCQ to grasp job stressors in the low-wage working categories. Moreover, to assess the effect of high strain on CHD, it is more accurate to use the low strain instead of the wider non-high strain as the reference category, since the adoption of the latter may contribute to bias the association to the null. Our results require replications on larger and diversified samples.

\section{Author affiliations}

${ }^{1}$ Department of Medicine and Surgery, EPIMED Research CentreEpidemiology and Preventive Medicine, University of Insubria, Varese, Italy

${ }^{2}$ Occupational Medicine Unit, Varese University Hospital, Varese, Italy
${ }^{3}$ Department of Health Sciences, University of Milano Bicocca, Monza, Italy ${ }^{4}$ IRCCS Multimedica, Sesto San Giovanni, Milano, Italy

Acknowledgements The authors thank all collaborators who helped in assessing baseline risk factors and collecting follow-up data. The authors also deeply recognise and thank the advices who reviewed the preliminary versions of this paper, and helped to improve it.

Contributors MMF conceived the research question, drafted the manuscript and is the principal investigator (PI) of the MONICA-Brianza and the SEMM study cohorts. GV and LB were responsible of the statistical analyses, contributed to interpretation of the data and revised the manuscript. $G G$ and GC are the PIs of the PAMELA study and of the MONICA-Brianza cohorts, respectively; they both helped with data interpretation and contributed critically to the Introduction and Discussion sections. All authors read and approved the final version of the paper, and agree to be accountable for all aspects of the work in ensuring that questions related to the accuracy or integrity of any part of the work are appropriately investigated and resolved.

Funding This work and the latest activities of the MONICA Brianza Study were mainly supported by the Health Administration of Regione Lombardia (grant numbers 17155/2004 and 10800/2009). The follow-up was partially supported with grants from the Italian Ministry of Health (grant 2012/597) and it was carried out in collaboration with the Centro di Epidemiologia, Sorveglianza e Promozione della Salute of the Istituto Superiore di Sanità in Roma.

Competing interests None declared.

Ethics approval San Gerardo Hospital, Monza, Italy.

Provenance and peer review Not commissioned; externally peer reviewed.

Data sharing statement Statistical details are available on request to the corresponding author.

Open Access This is an Open Access article distributed in accordance with the Creative Commons Attribution Non Commercial (CC BY-NC 4.0) license, which permits others to distribute, remix, adapt, build upon this work noncommercially, and license their derivative works on different terms, provided the original work is properly cited and the use is non-commercial. See: http:// creativecommons.org/licenses/by-nc/4.0/ 


\section{REFERENCES}

1. Olsen O, Kristensen TS. Impact of work environment on cardiovascular diseases in Denmark. J Epidemiol Community Health 1991;45:4-10.

2. Karasek RA. Job demands, job decision latitude, and mental strain: implications for job Redesign. Adm Sci Q 1979,24:285-308.

3. Belkic $\mathrm{KL}$, Landsbergis PA, Schnall $P$, et al. Is job strain a major source of cardiovascular disease risk? J Work Environ Health 2004;30:85-128.

4. Kivimaki M, Virtanen M, Elovainen $M$, et al. Work stress in the etiology of coronary heart disease-a meta-analysis. J Work Environ Health 2006;32:431-42.

5. Siegrist J. Adverse health effects of high-effort/low-reward conditions. J Occup Health Psychol 1996;1:27-41.

6. Kivimäki M, Nyberg ST, Batty GD, et al. Job strain as a risk factor for coronary heart disease: a collaborative meta-analysis of individual participant data. Lancet 2012;380:1491-7.

7. Netterstrøm B. Job strain as a measure of exposure to psychological strain. Lancet 2012;380:1455-6.

8. Choi B, Schnall P, Ko S, et al. Job strain and coronary heart disease. Lancet 2013;381:448.

9. Landsbergis $P$, Schnall P. Job strain and coronary heart disease. Lancet 2013;381:448.

10. Theorell T. Commentary triggered by the Individual Participant Data Meta-Analysis Consortium study of job strain and myocardial infarction risk. Scand J Work Environ Health 2014;40:89-95.

11. Kivimäki M, Kawachi I. Need for more individual-level meta-analyses in social epidemiology: example of job strain and coronary heart disease. Am J Epidemiol 2013;177:1-2.

12. Choi B, Dobson M, Landsbergis $\mathrm{P}$, et al. RE: "Need for more individual-level meta-analyses in social epidemiology: example of job strain and coronary heart disease". Am J Epidemiol 2013;178:1007-8.

13. Landsbergis PA, Dobson M, Schnall P. RE: "Need for more individual-level meta-analyses in social epidemiology: example of job strain and coronary heart disease". Am J Epidemiol 2013;178:1008-9.

14. Burr H, Formazin M, Pohrt A. Methodological and conceptual issues regarding occupational psychosocial coronary heart disease epidemiology. Scand J Work Environ Health 2016;42:251-5.

15. Ferrario MM, Veronesi G, Chambless LE, et al. The contribution of major risk factors and job strain to occupational class differences in coronary heart disease incidence: the MONICA Brianza and Pamela population-based cohorts. Occup Environ Med, 2011;68:717-22.

16. Cesana $G$, De Vito $G$, Ferrario $M$, et al. Ambulatory blood pressure normalcy: the PAMELA Study. J Hypertens Supp/ 1991;9:S17-23.

17. Houtman I, Kornitzer $M$, de Smet $P$, et al. Job stress, absenteeism and coronary heart disease European cooperative study (the JACE study): design of a multicentre prospective study. Eur J Public Health 1999;9:52-7.
18. World Health Organization. MONICA Psychosocial Optional Study Manual: suggested measurement instruments. Copenhagen: WHO Regional Office for Europe, 1989

19. Karasek R, Choi B, Ostergren PO, et al. Testing two methods to create comparable scale scores between the job content questionnaire (JCQ) and JCQ-like questionnaires in the European JACE Study. Int J Behav Med 2007;14:189-201.

20. Fransson El, Nyberg ST, Heikkilä K, et al. Comparison of alternative versions of the job demand-control scales in 17 European cohort studies: the IPD-Work consortium. BMC Public Health 2012;12:62.

21. Steptoe A, Kivimaki M. Stress and cardiovascular disease: an update on current knowledge. Annu Rev Public Heath 2013;34:337-54.

22. Choi B, Kurowski A, Bond $\mathrm{M}$, et al. Occupation-differential construct validity of the Job Content Questionnaire (JCQ) psychological job demands scale with physical job demands item: a mixed methods research. Ergonomics 2012;55:425-39.

23. Karasek R, Theorell T. Healthy work: stress, productivity, and the reconstruction of working life. New York: Basic Books Pub, 1990.

24. Cesana G, Ferrario M, Sega R, et al. Job strain and ambulatory blood pressure levels in a population-based employed sample of men in northern Italy. Scand J Work Environ Health 1996;22:294-305

25. Borchini R, Bertù L, Ferrario MM, et al. Prolonged job strain reduces time-domain heart rate variability on both working and resting days among cardiovascular-susceptible nurses. Int J Occup Med Environ Health 2015;28:42-51.

26. Emeny RT, Zierer A, Lacruz ME, et al. Job strain-associated inflammatory burden and long-term risk of coronary events: findings from the MONICA/KORA Augsburg case-cohort study. Psychosom Med 2013;75:317-25. 26

27. Kivimäki M, Nyberg ST, Fransson EI, et al. Associations of job strain and lifestyle risk factors with risk of coronary artery disease: a meta-analysis of individual participant data. CMAJ 2013;185:763-9.

28. Nyberg ST, Heikkilä K, Fransson El, et al. Job strain in relation to body mass index: pooled analysis of 160000 adults from 13 cohort studies. J Intern Med 2012;272:65-73.

29. Choi B, Dobson M, Ko S, et al. Job strain and lifestyle factors. CMAJ 2014;186:63-4.

30. Choi B, Ko SB, Landsbergis $P$, et al. Job strain and health-related behaviors. Am J Public Health 2014;104:e3.

31. Choi B, Dobson $M$, Landsbergis $P$, et al. Job strain and obesity. $J$ Intern Med 2014;275:438-40.

32. Smith PM, Mustard CA. Job strain, health behaviours and heart disease. CMAJ 2013;185:1251.

33. Smith P. Potentially misleading conclusions: job strain and health behaviors. Am J Public Health 2014;104:e4. 